\title{
Improvement of the optical properties after surface error correction of aluminium mirror surfaces
}

\author{
M. Ulitschka ${ }^{1 *} \mathbb{D}$, J. Bauer ${ }^{1}$, F. Frost ${ }^{1}$ and T. Arnold ${ }^{1,2}$
}

\begin{abstract}
Ion beam finishing techniques of aluminium mirrors have a high potential to meet the increasing demands on applications of high-performance mirror devices for visible and ultraviolet spectral range. Reactively driven ion beam machining using oxygen and nitrogen gases enables the direct figure error correction up to $1 \mu \mathrm{m}$ machining depth while preserving the initial roughness. However, the periodic turning mark structures, which result from preliminary device shaping by single-point diamond turning, often limit the applicability of mirror surfaces in the short-periodic spectral range. Ion beam planarization with the aid of a sacrificial layer is a promising process route for surface smoothing, resulting in successfully reduction of the turning mark structures. A combination with direct surface smoothing to perform a subsequent improvement of the microroughness is presented with a special focus on roughness evolution, chemical composition, and optical surface properties. As a result, an ion beam based process route is suggested, which allows almost to recover the reflective properties and an increased long-term stability of smoothed aluminium surfaces.
\end{abstract}

Keywords: Aluminium, lon beam etching, Mirrors, Oxygen, Nitrogen, lon beam smoothing

\section{Introduction}

Aluminium is a common construction material for fabrication of high-performance mirror devices since it exhibits high reflection coefficient in a broad spectral wavelength range from the infrared (IR) to the ultraviolet (UV) [1]. Due to its good mechanical machinability, light weight, low cost and high thermal conductivity, aluminium optics are rather attractive for spacecraft systems [2], high resolution imaging [3] and cryogenic applications $[4,5]$. Single-point diamond turning (SPDT) is a common manufacturing procedure for IR applications. The resulting SPDT grooves, so-called turning marks, result in undesired diffraction patterns in application and cause an overall degradation of optical performance in the VIS and UV due to scatter losses. Consequently, a

\footnotetext{
* Correspondence: melanie.ulitschka@gmx.de

${ }^{1}$ Leibniz Institute of Surface Engineering (IOM), Permoserstr. 15, 04318

Leipzig, Germany

Full list of author information is available at the end of the article
}

post-finishing step has to be applied for improving figure error and surface roughness [6]. Direct aluminium finishing techniques are under consideration in view of avoiding thermal stress during application when an additional amorphous coating such as nickel phosphorous (NiP) is used [2, 4, 5, 7]. Increasing demands on accuracy of surface quality for applications in the shortwavelength range claim improved ultra-precise surface machining techniques. Reactive ion beam etching (RIBE) is one promising surface machining technique to improve figure accuracy and surface finish [8-11].

During figure error correction by reactively-driven ion beam technologies using oxygen and nitrogen, the initial aluminium topography is exceedingly well preserved up to 400 $\mathrm{nm}$ and $1 \mu \mathrm{m}$ material removal depth, respectively. However, the process route is limited due to surface degradation caused by etch pit formation resulting from the precipitates within the aluminium matrix. A model scheme is suggested, based upon the in-situ formation of a surface oxide or nitride 
layer with a constant thickness of about $12-15 \mathrm{~nm}$. The chemically modified layer acts as a passivation layer inhibiting aluminium surface mobility and compositional inhomogeneity, thus preserving the initial surface topography during RIBE machining $[8,9]$. However, during irradiation of the aluminium surface with nitrogen gas, the reflectivity of the optical surface is decreased and surface errors situated in the microroughness regime are formed. The formed nitride layer can be efficiently removed by wet-chemical treatment [12]. However, a precise stopping of the wet-chemical etch needs to be ensured to avoid over-etching accompanied by a strong roughening of the aluminium surface.

Further investigations on aluminium smoothing of microroughness features with oxygen suggest a model scheme based on the incidence angle-dependent local sputter erosion [11, 13-17]. Thus, surface microroughness features with high slopes are gradually smoothed during processing $[11,18]$.

An additional issue for applications in the shortwavelength range are the periodic turning marks left by the cutting tool during SPDT, which may lead to undesired diffraction. The ion beam planarization procedure was originally proposed by Johnson and Ingersoll to remove polishing scratches on fused silica $[19,20]$ and is schematically shown in Fig. 1. Usually, the initial surface is covered by a smooth photoresist either by spin coating or spray coating. Subsequently, this sacrificial layer is removed by ion beam etching and the smooth surface is transferred into the underlying substrate.

To ensure an optimum transfer of the smooth sacrificial layer surface into the underlying aluminium substrate, RIBE planarization investigations were performed at $1.2 \mathrm{keV}$ with nitrogen. During investigations on ion beam planarization technique with the aid of a sacrificial layer using nitrogen, these surface error features were successfully reduced by overall $82 \%$ on RSA Al905 [21].

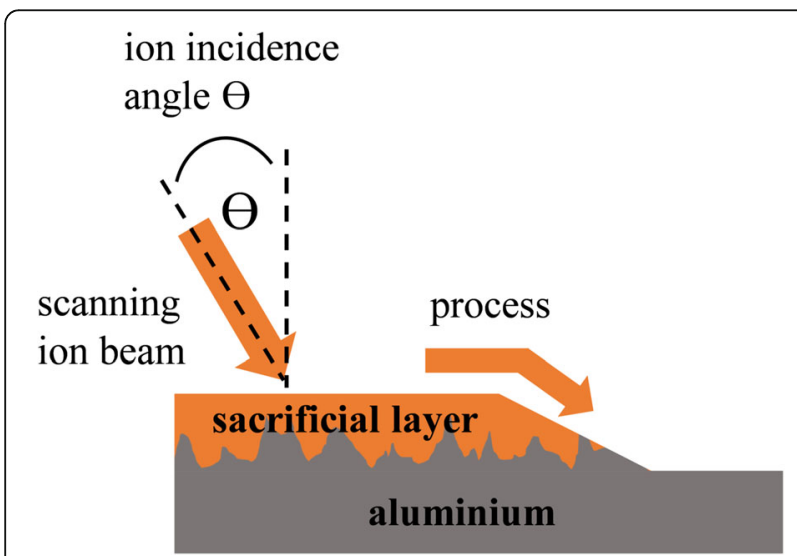

Fig. 1 Principle of ion beam planarization technique with the aid of a sacrificial layer
However, during ion beam processing with nitrogen an aluminium nitride layer is formed, which is accompanied by an increased microroughness and thus reduced reflectivity properties of the optical surface [21]. Since high reflection coefficient over a broad wavelength range is required for high-performance mirror devices, this paper is intended to face the drawbacks of the surface nitride after ion beam finishing with the nitrogen process for figure error correction or planarization by means of an optimized ion beam based post-processing step. In particular, subsequent ion beam irradiation with oxygen is applied to remove the nitride layer. Based upon the incidence angle-dependent local sputter erosion with oxygen, an additional reduction of the microroughness features formed during $\mathrm{N}_{2}$ RIBE machining is examined in detail. The formation of a favorable oxide layer is analyzed by using two different ion energies. Beside the improvement of the microroughness, the effect of RIBE finishing with oxygen is investigated considering the reflective properties and long-term stability of the optical surface.

\section{Experimental}

Ion beam machining experiments were conducted in an ultra-high vacuum chamber with a base pressure of $1.4 \times 10^{-5} \mathrm{~Pa}$. The ion beam was generated by a 13.56 $\mathrm{MHz}$ radio frequency (RF) ion source with a focusing triple grid extraction system with concavely shaped grids. The aluminium disc sample was mounted on a water-cooled sample holder which was attached to a five-axis motion system. Additionally, a Faraday cup was integrated into the sample holder permitting in situ spatially resolved beam current density measurements. The generated ion beam has a Gaussian shaped lateral current density distribution function and can be characterized by the full-width at half maximum (FWHM) and the maximum value. Nitrogen and oxygen gases were used for the generation of low-energy ion beams at beam energies of $\leq 1.5 \mathrm{keV}$. For the experiments the ion beam was scanned s-like over the surface with a constant velocity of $5 \mathrm{~mm} / \mathrm{s}$ and a $1 \mathrm{~mm}$ line pitch within a defined machining area in multiple repetitions. The machining depth can be controlled to a high degree via the process time. The machining area was defined by an aluminium mask with an opening diameter of $13 \mathrm{~mm}$. Though, for ion beam planarization with the aid of a sacrificial layer, the entire aluminium surface was coated with the negative tone ma-N 2405 photoresist and irradiated afterwards without an additional mask. The photoresist thickness was about $500 \mathrm{~nm}$, whereby 9 scan repetitions are necessary to remove the whole photoresist layer. The ion beam machining investigations were performed at normal ion incidence angle to the substrate surface. The aluminium planar disc samples were $47 \mathrm{~mm}$ in diameter 
and made of rapidly solidified aluminium (RSA) alloy Al905 [22] that have been single-point diamond turned. The ion beam process parameter for ion beam investigations are summarized in Table 1.

The sample topography was analysed by white light interferometry (WLI; Bruker NPFLEX ${ }^{\mathrm{ma}}$ 3D Surface Metrology System) and atomic force microscopy (AFM; Bruker Dimension ICON). For WLI, objectives with $5 \mathrm{x}$ magnification were used with $1 \times$ field of view multiplier in phase-shift interferometry mode. The image size was $1230 \mu \mathrm{m} \times 925 \mu \mathrm{m}$ with a pixel resolution of $640 \times 480$.

AFM was operated in tapping mode ${ }^{\mathrm{Tx}}$ in a $\mathrm{xy}$-closed loop configuration. Scanning areas of $3 \mu \mathrm{m} \times 3 \mu \mathrm{m}$ and $35 \mu \mathrm{m} \times 35 \mu \mathrm{m}$ were measured with a pixel resolution of $1024 \times 1024$. The AFM raw data are subjected to a plane correction performed in SPIP ${ }^{\mathrm{im}}$ software (version 6.0.14 by Image Metrology) [23]. The correction consists of a line-wise correction to subtract a polynomial fit of the 1st order and a correction to subtract a fitted polynomial function of the 3rd order.

The surface roughness was analysed by calculating the power spectral density function (PSD). A self-written MATLAB $^{\circ}$ script was employed for PSD calculation, angular integration, as well as composing and averaging of the individual isotropic PSD functions to obtain a characteristic, broad range PSD function. Measurements on aluminium surfaces were performed five times under the same conditions but at different positions to calculate an averaged PSD function. Since the RIBE planarization process is conducted on the whole substrate surface of $47 \mathrm{~mm}$ in diameter, each measurement has been performed eight times under the same conditions but at different positions. Root mean square (rms) roughness values were calculated by the square root of the integrated PSD in the spatial frequency ranges of $0.0024 \mu \mathrm{m}^{-1}-1.7 \mu \mathrm{m}^{-1}$ for waviness/roughness and $1.7 \mu \mathrm{m}^{-1}-34.7 \mu \mathrm{m}^{-1}$ for microroughness.

Time-of flight secondary ion mass spectrometry (ToFSIMS; IONTOF TOF SIMS 5) was used for depth profiling of the sample composition in the near surface region. The analysis was done by a $15 \mathrm{keV} \mathrm{Ga}$ ion beam, while the analysis scan field of $(50 \times 50) \mu \mathrm{m}^{2}$ is centered within the $(300 \times 300) \mu \mathrm{m}^{2}$ sputter crater. The depth calibrations were provided by WLI analysis of the sputter crater depths. The layer thicknesses are determined as the distance of the surface to the depth, where the signal is decreased to its half maximum value.

Reflectivity measurements were performed in a thin film analyzing system (Mikropack NanoCalc 2000) in the visible spectral range of $400-800 \mathrm{~nm}$ at five different positions to calculate averaged spectral characteristics. A polished p-type $\mathrm{Si}(100)$ sample was taken as reference. The reflectivity of the surface after each processing step with nitrogen or oxygen is therefore measured. For comparison, an untreated aluminium surface was measured under the same conditions.

\section{Results and discussion}

\section{Reactive ion beam etching with nitrogen}

Direct $\mathrm{N}_{2}$ RIBE machining is performed on a RSA Al905 sample with machining depths up to $2000 \mathrm{~nm}$ (see Fig. 2). The effect of RIBE machining on the surface roughness segmented into waviness/roughness regime and microroughness regime is summarized in detail in Table 2 and the corresponding spatial frequency ranges are marked in Fig. 2. For a detailed discussion of roughness

Table 1 lon beam process parameters of RIBE investigations on Al905 aluminium disc samples

\begin{tabular}{|c|c|c|c|c|c|c|c|}
\hline Process mode & Operating gas & Beam energy [eV] & Process pressure $[\mathrm{Pa}]$ & $\begin{array}{l}\text { FWHM } \\
{[\mathrm{mm}]} \\
\end{array}$ & Beam current [mA] & $\begin{array}{l}\text { Etch depth } \\
\text { [nm] }\end{array}$ & Scanning repetitions \\
\hline \multirow[t]{5}{*}{$\overline{\text { RIBE}^{1}}$} & $\mathrm{~N}_{2}$ & 1500 & $8.0 \times 10^{-4}$ & 7.1 & 4.30 & 49 & 1 \\
\hline & $\mathrm{N}_{2}$ & 1500 & $8.0 \times 10^{-4}$ & 7.2 & 4.54 & 196 & 4 \\
\hline & $\mathrm{N}_{2}$ & 1500 & $8.0 \times 10^{-4}$ & 7.1 & 4.36 & 492 & 10 \\
\hline & $\mathrm{N}_{2}$ & 1500 & $8.0 \times 10^{-4}$ & 7.2 & 4.34 & 1006 & 20 \\
\hline & $\mathrm{N}_{2}$ & 1500 & $8.0 \times 10^{-4}$ & 7.2 & 4.40 & 1998 & 40 \\
\hline \multirow[t]{5}{*}{$\mathrm{RIBE}^{2}$} & $\mathrm{~N}_{2}$ & 1500 & $8.0 \times 10^{-4}$ & 7.1 & 4.32 & 905 & 20 \\
\hline & $\mathrm{O}_{2}$ & 1500 & $1.1 \times 10^{-3}$ & 5.9 & 1.67 & - & 1 \\
\hline & $\mathrm{O}_{2}$ & 1500 & $1.1 \times 10^{-3}$ & 6.1 & 1.72 & 18 & 3 \\
\hline & $\mathrm{O}_{2}$ & 1500 & $1.2 \times 10^{-3}$ & 5.6 & 1.63 & 65 & 10 \\
\hline & $\mathrm{O}_{2}$ & 1500 & $1.1 \times 10^{-3}$ & 6.0 & 1.70 & 123 & 20 \\
\hline RIBE planarization & $\mathrm{N}_{2}$ & 1200 & $1.6 \times 10^{-3}$ & 8.4 & 1.89 & & 9 \\
\hline \multirow[t]{2}{*}{ RIBE finishing } & $\mathrm{O}_{2}$ & 1500 & $1.3 \times 10^{-3}$ & 4.3 & 1.68 & & 1 \\
\hline & & 600 & $8.5 \times 10^{-4}$ & 6.5 & 1.15 & & 4 \\
\hline
\end{tabular}

Ion beam machining investigations for the purpose of quantitative comparison of increasing material removal depth (index 1) with almost retained ion beam processing parameter. In the second section (index 2) the subsequent ion beam machining experiments with increasing material removal depths using oxygen operating gas is presented and in section $3 \mathrm{RIBE}$ planarization and $\mathrm{O}_{2}$ finishing at two different beam energies of $0.6 \mathrm{keV}$ and $1.5 \mathrm{keV}$ 


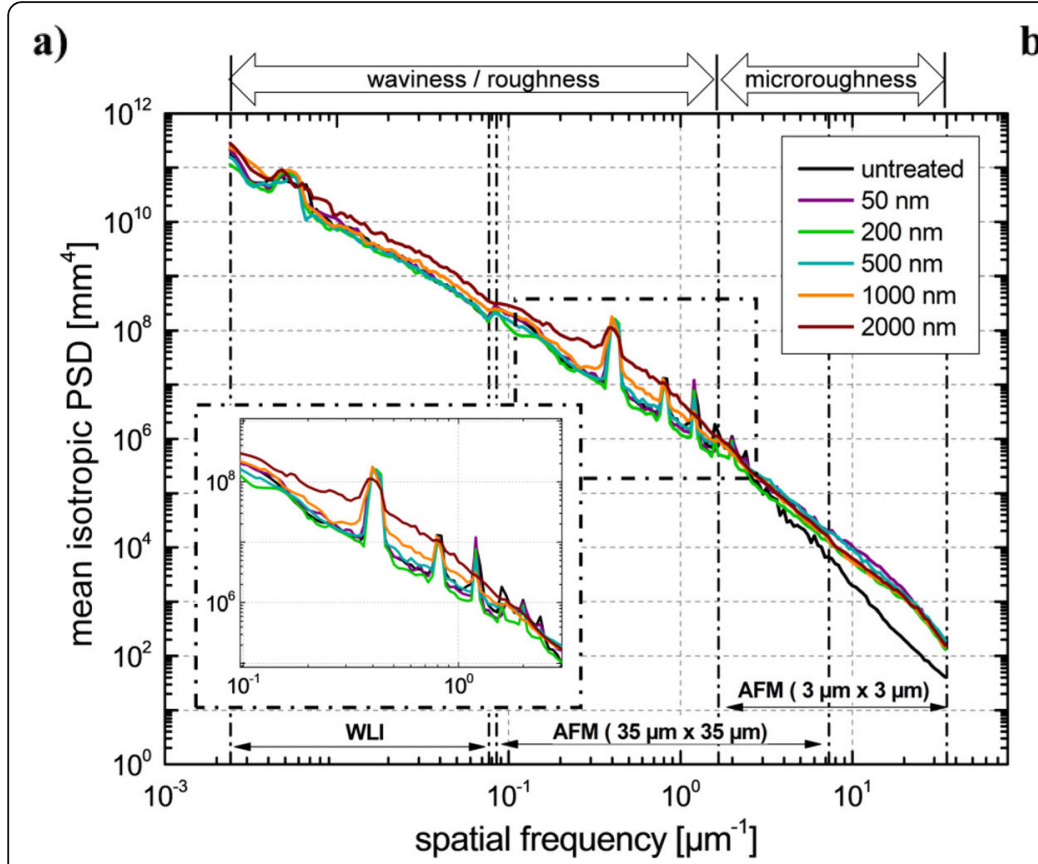

b)

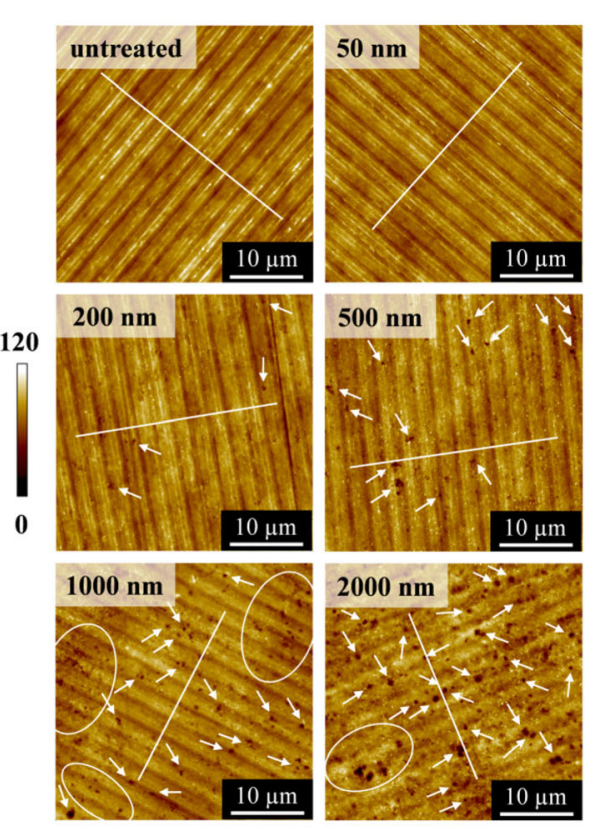

Fig. 2 a PSD functions of the untreated Al905 surface and after RIBE machining with $\mathrm{N}_{2}$ at different material removal depths and $\mathbf{b}$ ) corresponding AFM measurements (z-scale in $\mathrm{nm}$ ) with scan sizes of $35 \mu \mathrm{m} \times 35 \boldsymbol{\mu m}$

evolution, the spatial wavelength range, where the turning marks are situated, is illustrated enlarged by means of an inset in Fig. 2a. Additionally, the positions for cross section profiles shown in Fig. 3a are represented by solid lines in the AFM images in Fig. 2b.

The untreated aluminium Al905 surface is characterized by turning marks with a period of $2.5 \mu \mathrm{m}$ corresponding to the peak at $0.4 \mu \mathrm{m}^{-1}$ with several superstructures at $0.8 \mu \mathrm{m}^{-1}, \quad 1.2 \mu \mathrm{m}^{-1}, \quad 1.6 \mu \mathrm{m}^{-1}$, $2.0 \mu \mathrm{m}^{-1}$ and $2.4 \mu \mathrm{m}^{-1}$ in the PSD function. During nitrogen processing, the PSD function in the spatial frequency range below $3 \mu \mathrm{m}^{-1}$ remains almost unchanged up to $500 \mathrm{~nm}$ material removal. However, with increasing material removal, the PSD peaks corresponding to the turning mark structures are continuously decreased and almost completely disappeared after $2000 \mathrm{~nm}$ material removal. One exception is the bump at $0.4 \mu^{-1}$ corresponding to the $2.5 \mu \mathrm{m}$ spaced turning marks. Hence, the turning marks are gradually smoothed and the turning mark height decreases with increasing material removal (see Fig. 3a). Consequently, the turning mark height decreases to about $(14.6 \pm 1.3) \mathrm{nm}$ after 500 $\mathrm{nm}$ removal compared to the initial height of $(23.1 \pm 2.1)$ $\mathrm{nm}$. However, with increasing material removal of 1000 $\mathrm{nm}$ and $2000 \mathrm{~nm}$, the turning mark height is marginally further decreased to $(14.1 \pm 1.6) \mathrm{nm}$ and $(11.1 \pm 2.3) \mathrm{nm}$, respectively.

This might be caused by a contrary process of increased surface degradation due to enhanced etch pit formation resulting in an increased PSD function in the spatial frequency range where the turning marks are situated (see Fig. 2). Consequently, the PSD deviations

Table 2 Surface roughness of aluminium Al905 divided into microroughness, waviness/roughness and full range roughness. The roughness values are calculated for each machining depth in the spatial frequency ranges of $0.0024 \mu \mathrm{m}^{-1}-1.7 \mu \mathrm{m}^{-1}$ for waviness/ roughness and $1.7 \mu^{-1}-34.7 \mu \mathrm{m}^{-1}$ for microroughness

\begin{tabular}{lllll}
\hline RSA Al905 & Machining depth [nm] & Microroughness [nm rms] & Roughness + waviness [nm rms] & $\begin{array}{l}\text { Full range } \\
\text { [nm rms] }\end{array}$ \\
\hline Untreated & & $3.8 \pm 1.2$ & $9.5 \pm 1.7$ & $10.2 \pm 2.3$ \\
RIBE N 2 & 49 & $4.3 \pm 0.8$ & $9.6 \pm 1.5$ & $10.6 \pm 1.7$ \\
& 196 & $4.1 \pm 0.4$ & $8.5 \pm 1.2$ & $9.6 \pm 1.2$ \\
& 492 & $4.2 \pm 0.5$ & $9.3 \pm 1.3$ & $10.2 \pm 1.4$ \\
& 1006 & $4.4 \pm 0.7$ & $9.8 \pm 0.8$ & $10.9 \pm 2.0$ \\
& 1998 & $4.2 \pm 0.5$ & $12.2 \pm 0.7$ & $12.9 \pm 1.8$ \\
\hline
\end{tabular}




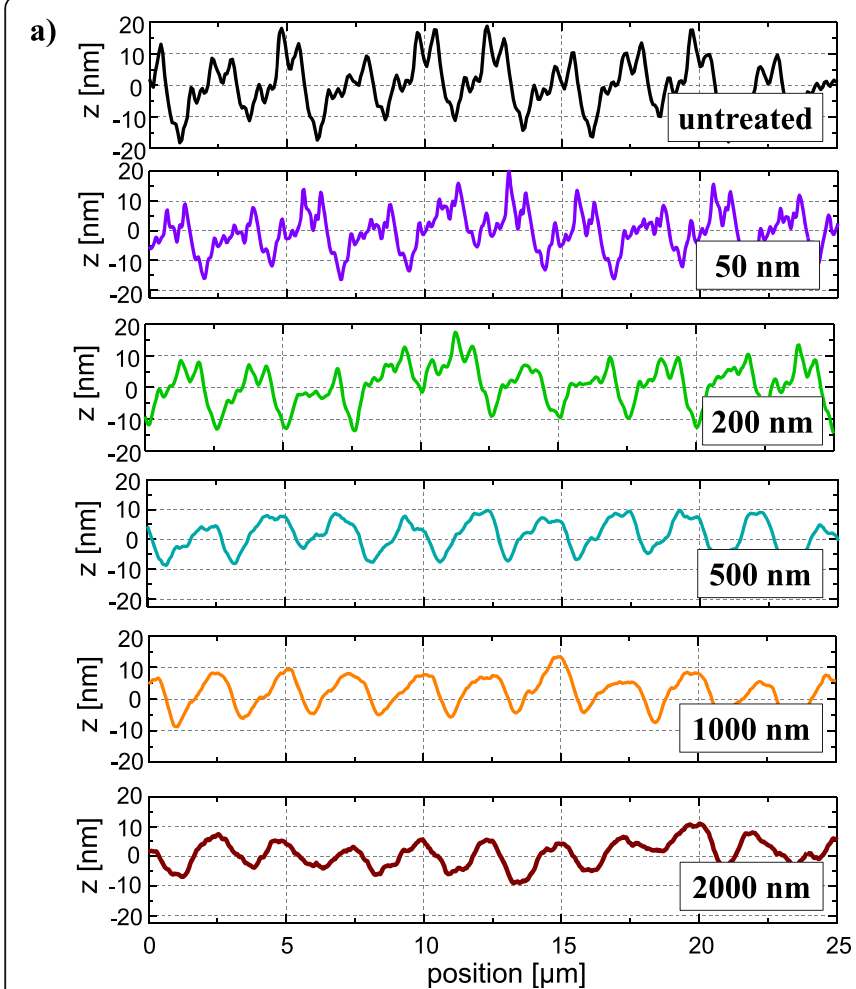

b)

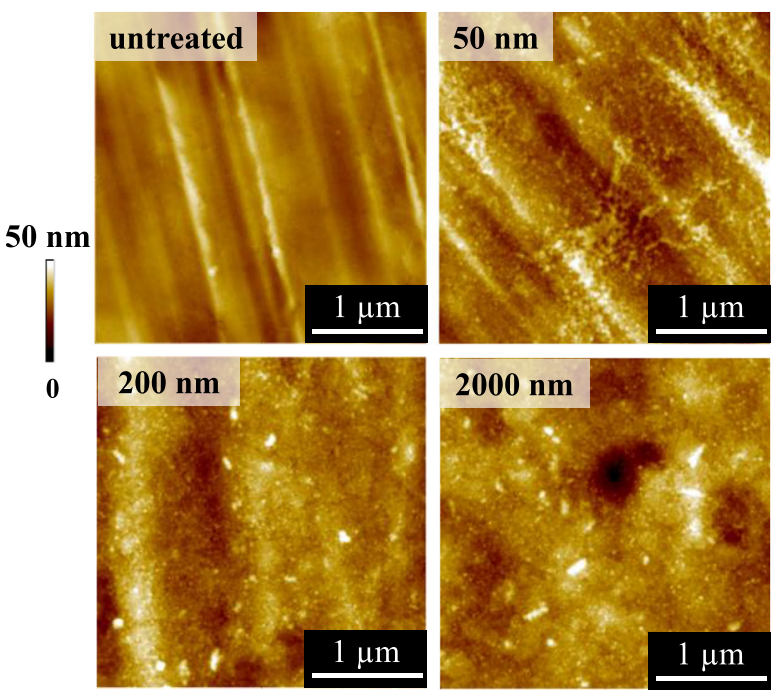

Fig. 3 a Cross section profiles corresponding to the solid lines in the AFM measurements in Fig. 2 of the untreated Al905 surface and after $N_{2}$ RIBE machining at different material removal depths. b AFM measurements (z-scale in nm) of the untreated Al905 surface and after N2 RIBE machining at different material removal depths

corresponding to the turning mark seem to be superimposed by the surface degradation.

Additionally, the PSD spectrum is increased in the spatial frequency range above $2.5 \mu \mathrm{m}^{-1}$ up to maximum of one order of magnitude (see Fig. 2a). Thus, the microroughness is marginally increased after $50 \mathrm{~nm}$ removal to $(4.3 \pm 0.8) \mathrm{nm}$ rms compared to $(3.8 \pm 1.2) \mathrm{nm}$ rms of the untreated surface. This is assumed to result from the formation of nanoscopic granules irregularly distributed over the whole surface (see Fig. 3b). Once this structure has been formed, it remains almost unchanged up to $2 \mu \mathrm{m}$ machining depth. Though, additionally larger particles are formed above $200 \mathrm{~nm}$ removal. Investigations on RIBE machining with nitrogen operating gas reveal a roughness preservation up to $1 \mu \mathrm{m}$ machining depth with moderate surface degradation up to $2 \mu \mathrm{m}$. Hence, the depth range for RIBE processing is significantly increased by using nitrogen as operating gas compared to oxygen [8]. This enhanced functionality is especially relevant in figure error correction of optical aluminium devices.

ToF-SIMS measurements shown in Fig. 4 reveal, that instantly during the first $50 \mathrm{~nm}$ material removal, an approximately $15.1 \mathrm{~nm}$ thick nitride layer is formed. With increasing material removal depth, the nitride layer thickness hardly changes and results in about (14.7 \pm 0.9) $\mathrm{nm}$ averaged for all machining depths. Consequently, a comparable model scheme can be suggested for RIBE processing with $\mathrm{N}_{2}$ operating gas as already observed during oxygen machining [8]. The nitride layer formed also seems to act as a passivation layer which is eroded and simultaneously newly formed during processing, thus preserving the initial roughness. Though, the aluminium surface after RIBE machining with nitrogen exhibits a yellowish color. Since AlN is transparent in the visible spectral range, compositional or structural defects or impurities should be the reason for optical absorption and thus a changing color [24]. Consequently, reflectivity measurements were performed for each machining depth in comparison to the untreated surface (see Fig. 5).

The untreated aluminium surface reveals high reflectivity over the whole measured wavelength range in the visible spectra with values of about $80-85 \%$. However, during nitrogen processing the reflectivity decreases strongly over the whole measured wavelength range, especially at lower wavelength ranges below $700 \mathrm{~nm}$. This might be caused by the formation of surface error features in the microroughness regime since these features have a considerable impact on light scattering 

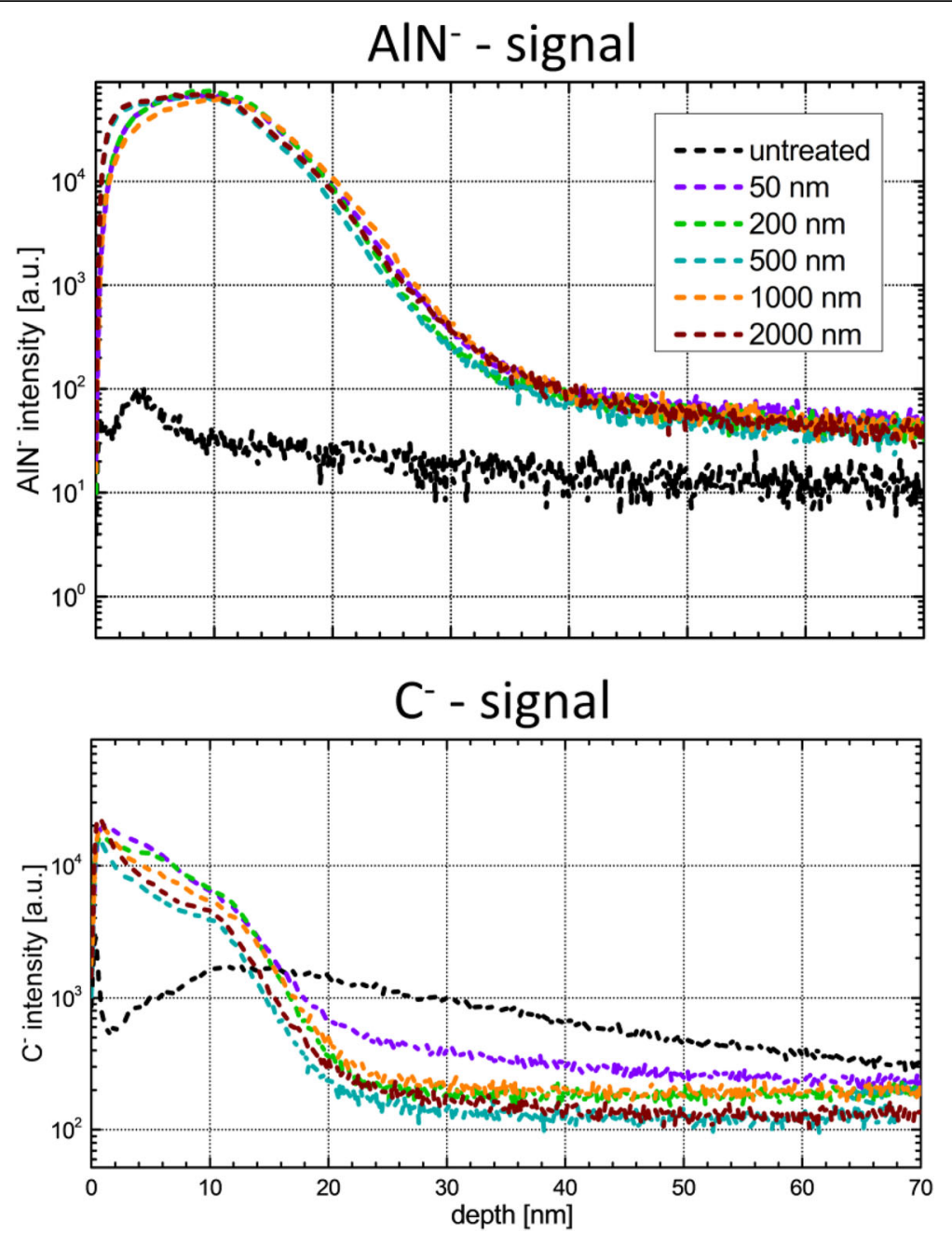

Fig. 4 ToF-SIMS depth profiles of RSA Al905 after RIBE machining with nitrogen operating gas at different machining depths. The extent of a nitride surface layer is represented by the $\mathrm{AIN}^{-}$- signal (top). The carbon is represented by the $\mathrm{C}^{-}$- signal (bottom)

influencing the spectral reflection characteristics in the visible spectral range due to broad halo scattering [25, 26]. It is particularly noticeable, that the lowest reflectivity is observed after the least material removal of $50 \mathrm{~nm}$. This may be due to the formation of the granules without remarkable smoothing of the turning marks situated in the microroughness regime (see Fig. 3).

In general, the reflectivity increases with increasing material removal depth. Minor deviations from this trend are found on the sample after $\mathrm{N}_{2}$ irradiation with $500 \mathrm{~nm}$ material removal. In comparison to RIBE investigations after $1000 \mathrm{~nm}$ material removal, the reflectivity is slightly enhanced. The $500 \mathrm{~nm}$ sample exhibits the lowest carbon incorporation while a distinct reduction of the turning mark structure situated in the microroughness regime is observed. Thus, also the carbon content might be a factor influencing the reflective properties of the surface.
In general, the maximum carbon intensity is detected at the surface and decreases with increasing depth for all RIBE machining depth. Indeed, the carbon incorporation is deeper for lower material removal depths of $50 \mathrm{~nm}$ and $200 \mathrm{~nm}$ (see Fig. 4). The detected carbon within the aluminium nitride layer is $6.9 \mathrm{~nm}$ after $50 \mathrm{~nm}$ material removal. In contrast, after $1000 \mathrm{~nm}$ and $2000 \mathrm{~nm}$ machining depth, the detected carbon signal has a thickness of $4.1 \mathrm{~nm}$ and $2.8 \mathrm{~nm}$, respectively.

In general, aluminium surface modification via nitrogen ion implantation is favorable for a number of technological applications like piezoelectric materials for surface acoustic wave devices or barrier layers in semiconductors [27, 28]. For such applications, deep nitrogen diffusion into subsurface layers is appropriate [29]. Due to the limited implantation depth of nitrogen ions, deep nitriding can thus only be achieved at sufficiently high temperatures [28-30]. During low- 


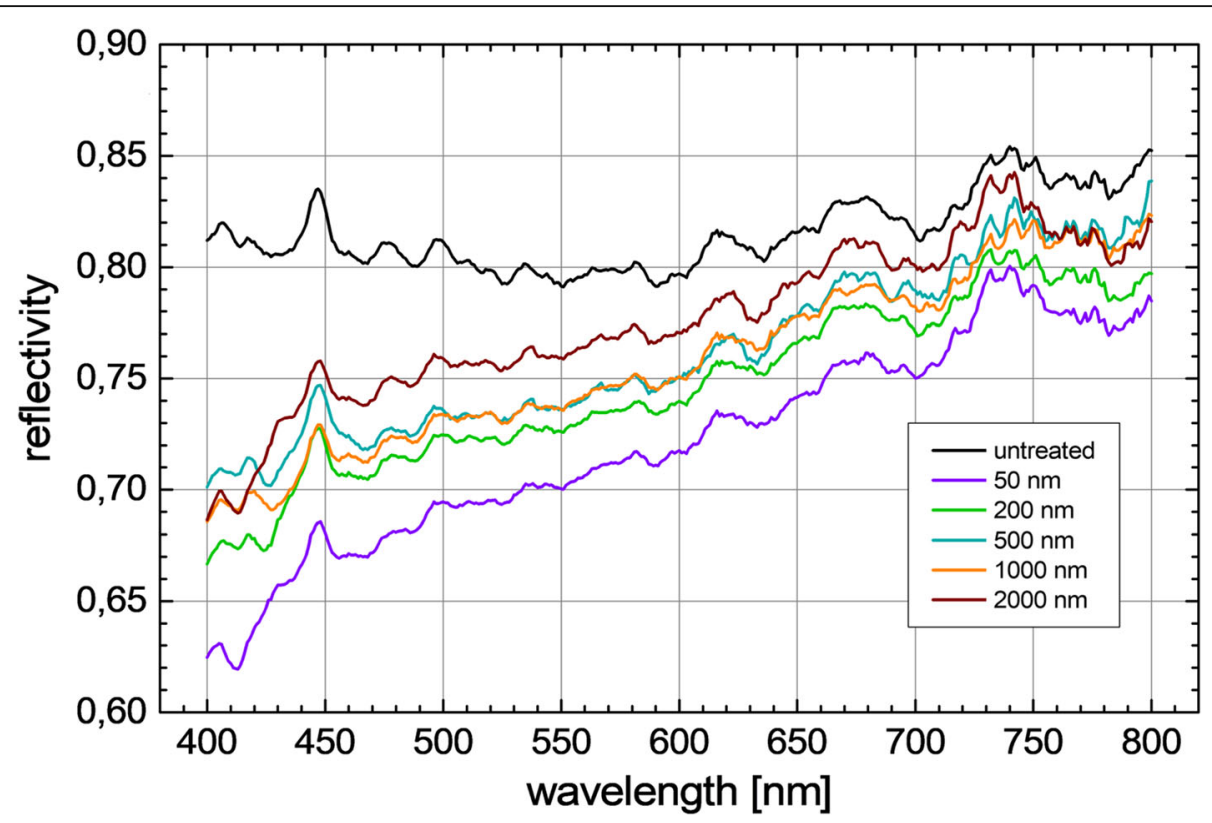

Fig. 5 Reflectivity in the visible spectral range of the untreated aluminium surface and after RIBE machining with nitrogen operating gas at different machining depths

energy ion bombardment the native oxide layer is reduced and a continuous AlN-layer near the surface is formed. Additionally, a diffusional gradient of aluminium from the underlying bulk towards the surface results in a process-specific nitride thickness [29-32].
Similar observations were made during the present study.

Investigations on ion beam etching of an aluminium surface with $\mathrm{N}_{2}$ operating gas at $1.5 \mathrm{keV}$ result in the formation of an aluminium nitride layer with a nearly-

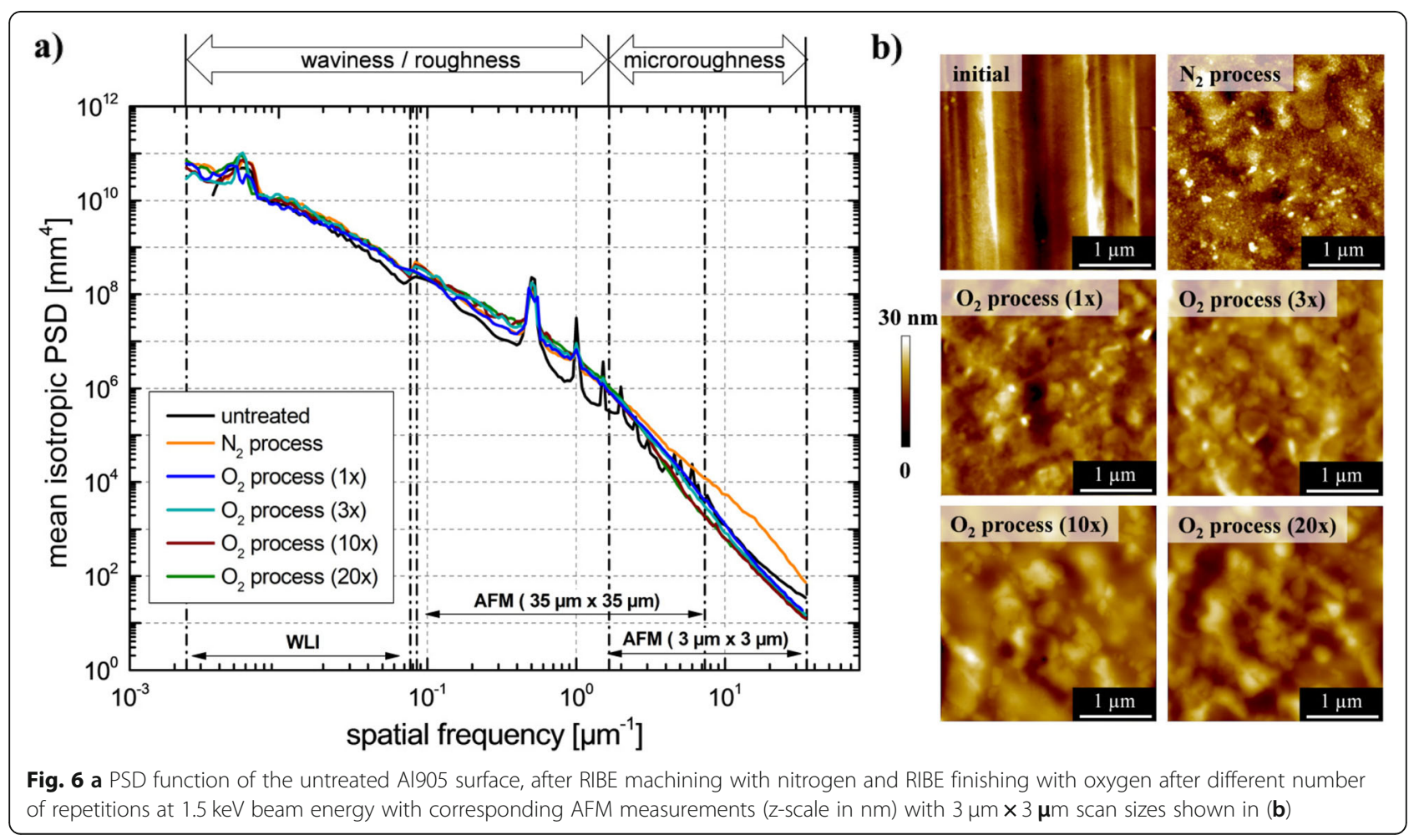


constant thickness of about $(14.7 \pm 0.9) \mathrm{nm}$ for all machining depths from $50 \mathrm{~nm}-2000 \mathrm{~nm}$ material removal. However, the aim of these investigations is no specifically nitriding of the aluminium surface but utilizing the formation of an AlN layer with nearly-constant thickness for roughness preservation during ion beam machining.

\section{RIBE finishing with oxygen}

In order to improve the reflectivity and reduce the microroughness formed during nitrogen machining, a RIBE smoothing step using oxygen at $1.5 \mathrm{keV}$ beam energy is subsequently applied. Firstly, the whole surface of another aluminium Al905 disc sample is eroded using $\mathrm{N}_{2}$ RIBE machining up to $900 \mathrm{~nm}$ removal depth (see Fig. 6). The ion beam process conditions are kept equally to RIBE investigations discussed in section 3.1. Figure 6a shows a slight increase of the whole PSD function during $\mathrm{N}_{2}$ RIBE machining, which is attributed to the formation of etch pits and the nanoscopic granules. Subsequently, the material removal depth using $\mathrm{O}_{2} \mathrm{RIBE}$ is gradually increased via increasing number of scanning repetitions within the defined machining area. One single repetition includes the s-like scanning of the ion beam over the whole machining area. Thus, multiple repetitions define a specific material removal depth (see Table 3).

Independent on the material removal depth, the surface roughness in the microroughness regime is strongly reduced during oxygen machining, resulting in a decrease of all PSD spectra in the spatial frequency range above $2 \mu \mathrm{m}^{-1}$. Though, in the spatial frequency range below $2 \mu \mathrm{m}^{-1}$ the PSD functions nearly merge (see Fig. 6a).

One scanning repetition results in the removal of the granular structure and consequently in a reduced microroughness of about $(3.4 \pm 0.5) \mathrm{nm}$ rms compared to $(4.5 \pm 0.7) \mathrm{nm}$ rms after $\mathrm{N}_{2}$ machining (see Table 3). With increasing material removal after $3 x, 10 x$ and $20 x$ repetitions, no distinct difference is observed resulting in microroughness values of $(3.1 \pm 0.3) \mathrm{nm} \mathrm{rms},(3.3 \pm 0.5)$ $\mathrm{nm}$ rms and $(3.5 \pm 0.9) \mathrm{nm}$ rms, respectively.

Table 3 Surface roughness in the microroughness regime of the untreated aluminium Al905 surface, after RIBE machining with $\mathrm{N}_{2}$ and subsequently $\mathrm{O}_{2}$ gas at $1.5 \mathrm{keV}$ beam energy

\begin{tabular}{llll}
\hline RSA Al905 & Repetitions & $\begin{array}{l}\text { Machining } \\
\text { depth }[\mathrm{nm}]\end{array}$ & $\begin{array}{l}\text { Microroughness } \\
{[\mathrm{nm} \mathrm{rms}]}\end{array}$ \\
\hline Untreated & - & & $3.4 \pm 0.8$ \\
RIBE N $_{2}$ & 20 & 905 & $4.5 \pm 0.7$ \\
RIBE O $_{2}$ & 1 & - & $3.4 \pm 0.5$ \\
& 3 & 18 & $3.1 \pm 0.3$ \\
& 10 & 65 & $3.3 \pm 0.5$ \\
& 20 & 123 & $3.5 \pm 0.9$ \\
\hline
\end{tabular}

For a detailed discussion of microroughness evolution during $\mathrm{O}_{2}$ RIBE finishing, the gradient distributions of the microroughness features present on the aluminium surface after $\mathrm{N}_{2}$ RIBE and $\mathrm{O}_{2}$ finishing were calculated from the AFM measurements depicted in Fig. 6b. The gradient norm distribution is produced by assigning the local value of the maximal slope to each pixel via SPIP ${ }^{\mathrm{m}}$ software. The gradient distributions in Fig. 7 show, that already after one scanning repetition RIBE machining with oxygen the local surface error slopes are shifted to lower values. However, with increasing scanning repetitions and therefore an increased material removal, marginal further shifting of the gradient distributions to lower values is observed.

Due to the ion incidence angle dependent sputter erosion described by Carter et al. [14-17] and a detailed discussion of the microroughness evolution during the interaction of a low-energy ion beam with an Al905 surface described in a previous study [11, 18], surface areas with high slopes show an enhanced removal rate resulting in a gradually smoothing of these roughness features. These results are in good agreement with the roughness evolution illustrated in Fig. 6. Marginal material removal generated within $1 \mathrm{x}$ repetition of $\mathrm{O}_{2} \mathrm{RIBE}$ is sufficient to reduce the surface error features situated in the microroughness regime, which were formed during $\mathrm{N}_{2}$ RIBE machining. In contrast, increasing $\mathrm{O}_{2}$ finishing repetitions $(>10 x)$ lead to the formation of additional etch pits on the aluminium resulting in marginal degradation of the optical surface.

Beside the improvement of the microroughness, $\mathrm{O}_{2}$ finishing additionally restores the optical properties to a considerable fraction (see Fig. 8). Consequently, the reflectivity is increased over the whole measured wavelength range of $400 \mathrm{~nm}-800 \mathrm{~nm}$. Though, the initial reflectivity of an untreated surface was not achieved. In particular, scanning repetitions up to 10x lead to similar reflectivity improvement. However, after 20 repetitions, where an increased etch pit formation is observed, the reflectivity decreases again in the wavelength range of $450 \mathrm{~nm}-650 \mathrm{~nm}$.

As an additional factor of influence, the reflective properties change with storage time of the samples in air under lab conditions. To examine the effect of storage time, the measurements were repeated after about 1 year storing in air, respectively. Fig. 8b shows a comparison of the reflectivity spectra (solid lines) of the freshly prepared aluminium surfaces of Fig. 8a to repeated reflectivity measurements after 1 year storage in air (dotted lines). Note, for reasons of clarity, only two exemplary curves of the repeated measurement on surfaces after subsequently applied $\mathrm{O}_{2}$ finishing are shown in Fig. 8b.

The surfaces after $3 x$ and 10x repetitions reveal similar improvement. Indeed, the surfaces which were 


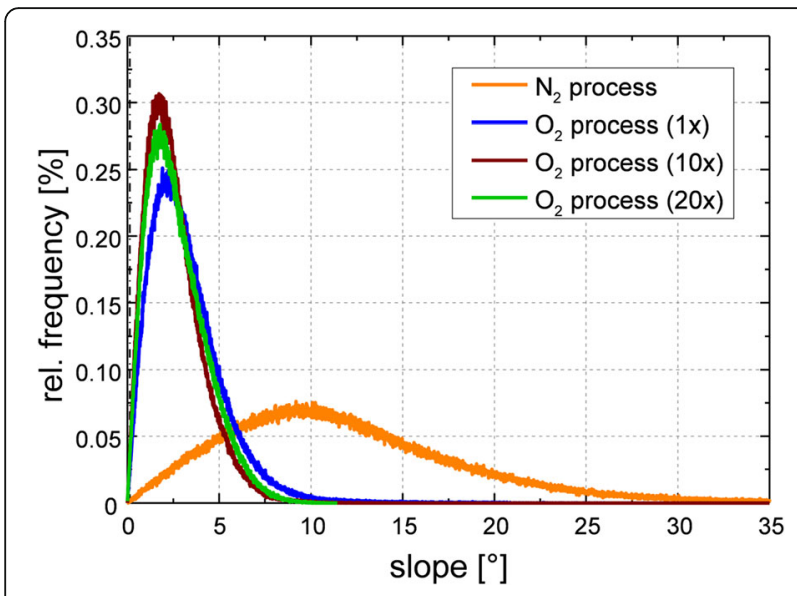

Fig. 7 Gradient distributions of Al905 surface errors after RIBE machining with nitrogen operating gas and after subsequent RIBE finishing with oxygen operating gas after $1 \mathrm{x}, 10 \mathrm{x}$ and $20 \mathrm{x}$ repetitions at $1.5 \mathrm{keV}$ beam energy

subsequently irradiated with oxygen reveal a slight improvement of the reflectivity, whereas the surface irradiated with $\mathrm{N}_{2}$ again shows an increased improvement. Specific oxidation of AlN is a temperature-dependent process, controlled by reaction or diffusion resulting in several $\mu \mathrm{m}$ oxide thickness [33]. However, the contact of the freshly prepared surface with ambient air after ion beam irradiation might result in a modification of the top surface layer due to reactions with oxygen at room temperature, affecting the reflection properties during storage [34]. To clarify this thesis, SIMS investigations have been performed before and after storage.

Firstly, the effect of $\mathrm{O}_{2}$ finishing is examined. The SIMS depth profiling investigations are performed on the freshly prepared surface (see Fig. 9). The carbon signal shows a shifting during $\mathrm{O}_{2}$ finishing deeper into the modified top layer. The graphite plasma anchor within the used ion source is in direct contact to the oxygen or nitrogen plasma. Thus, the anchor, but also the graphite ion extraction grids, act as a source of impurity and lead to carbon incorporation into the surface. After $\mathrm{N}_{2}$ processing, the carbon content is highest directly at the surface and decreases exponentially within the surface layer (see Fig. 4 for comparison). In contrast, after subsequently applied $\mathrm{O}_{2}$ finishing, the carbon is implanted into the surface layer with a peak content at about 10 $\mathrm{nm}$ underneath the surface (see Fig. 9). Thus, the incorporated carbon might be an influencing factor on the reflection properties shown in Fig. 8.

Figure 9 further shows the strongly modified surface composition during $\mathrm{O}_{2}$ RIBE finishing. After $1 \times$ repetition, an about $15.9 \mathrm{~nm}$ thick oxide layer is formed. Though, the oxide layer thickness is nearly independent on the material removal depth, since the thicknesses calculated after $3 \mathrm{x}$ and $20 \mathrm{x}$ repetitions are $16.8 \mathrm{~nm}$ and $16.1 \mathrm{~nm}$, respectively. Consequently, the surface oxidation process described in a former study has to be considered [8].

Additionally, the $\mathrm{AlO}_{2}{ }^{-}$- signal near the surface increases obviously while the corresponding $\mathrm{AlN}^{-}$- signal decreases strongly with increasing material removal. The nitride layer formed during $\mathrm{N}_{2}$ machining is continuously eroded and displaced with oxygen during subsequent $\mathrm{O}_{2}$ finishing. Similar observations were discussed by Yue et al. and Kurbutowicz et al. during thermal oxidation of AlN ceramic substrates in the temperature range of $850^{\circ} \mathrm{C}-1100^{\circ} \mathrm{C}[35,36]$. Depending on the composition of the atmosphere, a series of physical and chemical processes take place. However, ion beam treatment is performed with a water-cooled samples holder almost at room temperature, thus for a basic
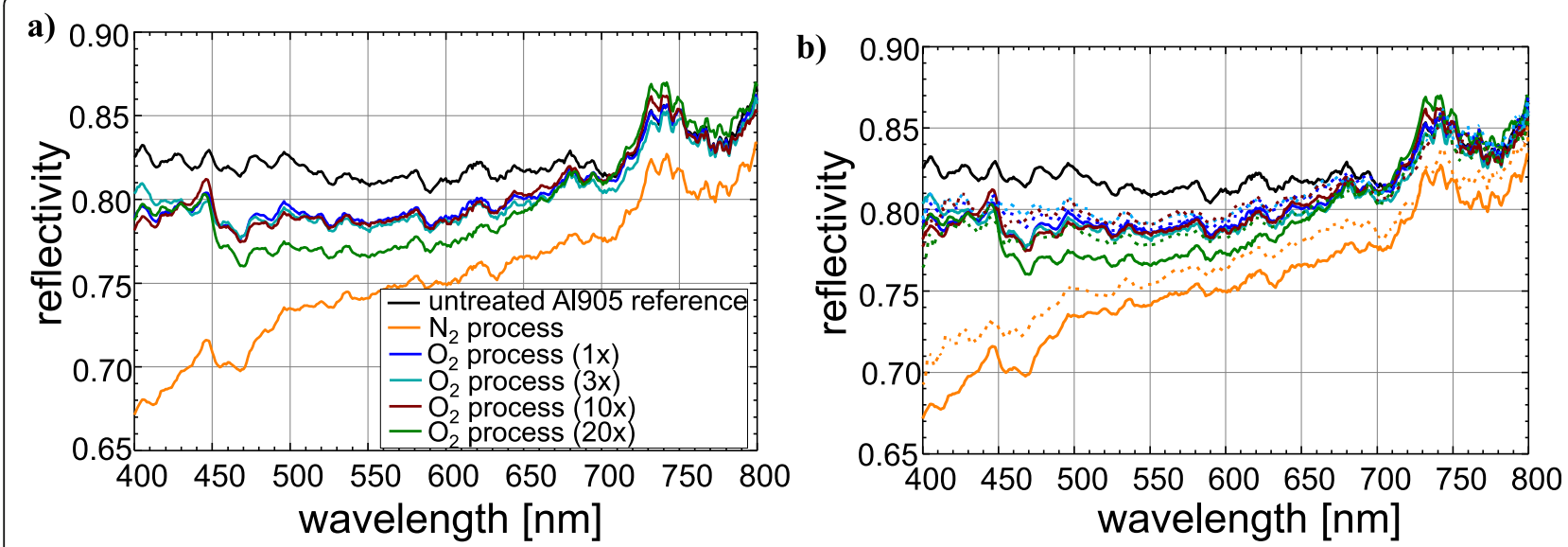

Fig. 8 a Reflectivity in the visible spectral range of the initial aluminium surface, after RIBE machining with nitrogen operating gas and subsequent RIBE finishing with oxygen operating gas with $1 x, 3 x, 10 x$ and $20 x$ repetitions. The measurements were repeated after about 1 year. The resulting measurements (dotted lines) are additionally shown in $\mathbf{b}$ ) compared to the measurements performed on the freshly prepared surfaces (solid lines). 


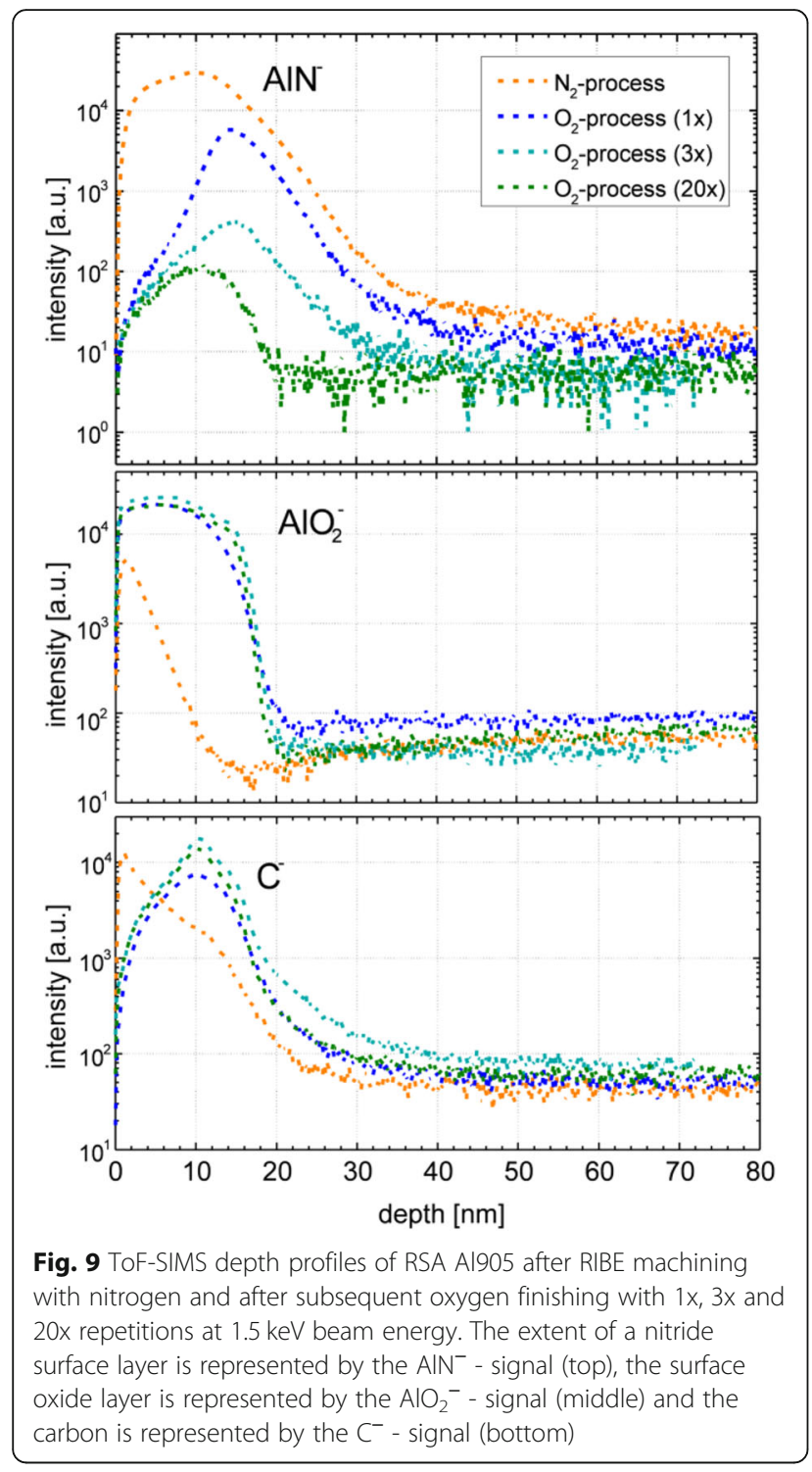

understanding kinetic processes need to be addressed. Hence, surface diffusion processes, ion implantation, sputter erosion, and forward sputtering of matrix atoms after resonant primary ion collision seem to be the driving forces for surface modification within the present investigations.

Additional to the improved reflection properties, the oxidation process observed during $\mathrm{O}_{2}$ finishing procedure shows an impact on the long-term stability of the reflection properties observed in Fig. 8b. During the process, already an effective surface modification and oxygenenrichment is introduced, leading to a reduced reaction with oxygen in ambient air, when the sample is stored.

Within this context, ToF-SIMS depth profiling was also performed on the surface after storage in air. However, a comparison of the depth profiles, individually normalized to the respective intensity of the aluminium matrix, reveal no significant changes over time. The formation of an oxide on the freshly prepared nitride surface during contact with air is still assumed, since ToFSIMS depth profiles indicate an oxygen-containing surface layer. However, according to the performed measurements, no increased oxygen content within this layer is observed after storage.

\section{Reactive ion beam planarization with the aid of a sacrificial layer combined with RIBE-based finishing using oxygen}

Hereafter, ion beam planarization of Al905 with the aid of a sacrificial layer and subsequent $\mathrm{O}_{2}$ finishing are elucidated. A detailed discussion of RIBE planarization process of optical aluminium surfaces with the aid of a sacrificial layer is described elsewhere [21]. As brief summary, the ion beam process parameter and application steps of the sacrificial layer were optimized to ensure an optimum transfer of the smooth sacrificial layer surface into the underlying aluminium substrate. Consequently, RIBE planarization investigations were performed at 1.2 $\mathrm{keV}$ with nitrogen since the roughness of the sacrificial layer was preserved during irradiation without surface degradation. Additionally, a maximum aluminium removal of $50 \mathrm{~nm}$ during processing was not exceeded. Consequently, iterative planarization runs result in significantly reduced turning mark features by overall $82 \%$ after two runs. Additionally, marginal surface degradation due to the formation of single etch pits with sizes mainly in the sub-micrometer range is observed.

A special focus is set on the oxygen ion energy in this investigation. In accordance to the ion energy dependent erosion process at normal ion incidence, $\mathrm{O}_{2}$ RIBE finishing investigations are performed at $0.6 \mathrm{keV}$ and $1.5 \mathrm{keV}$ [37]. Despite the sputtering yield and thus the etch process efficiency are reduced at $0.6 \mathrm{keV}$, the ion implantation depth and forward sputtering of matrix atoms are reduced in general. Hence, at the expense of process time a less destructive sputter etch process with a reduced necessary removal depth can be expected to convert the nitride into an oxide layer.

The impact on oxide formation and nitride declining during ion beam irradiation is analyzed in the following with distinct focus on roughness evolution, surface modification and reflectivity. During $\mathrm{O}_{2}$ RIBE finishing, the ion beam was scanned s-like over the surface with a constant velocity of $4 \mathrm{~mm} / \mathrm{s}$ and $1 \mathrm{~mm}$ line pitch within 1 repetition at $1.5 \mathrm{keV}$ and 4 repetitions at $0.6 \mathrm{keV}$ beam energy, respectively. Figure 10a shows, that the turning marks corresponding to the deviations in the spatial frequency range of $0.3 \mu \mathrm{m}^{-1}-2 \mu \mathrm{m}^{-1}$, remain almost unchanged after $\mathrm{O}_{2}$ finishing, independent on the ion beam energy applied. Moreover, both PSD spectra are remarkably decreased in the spatial frequency range 


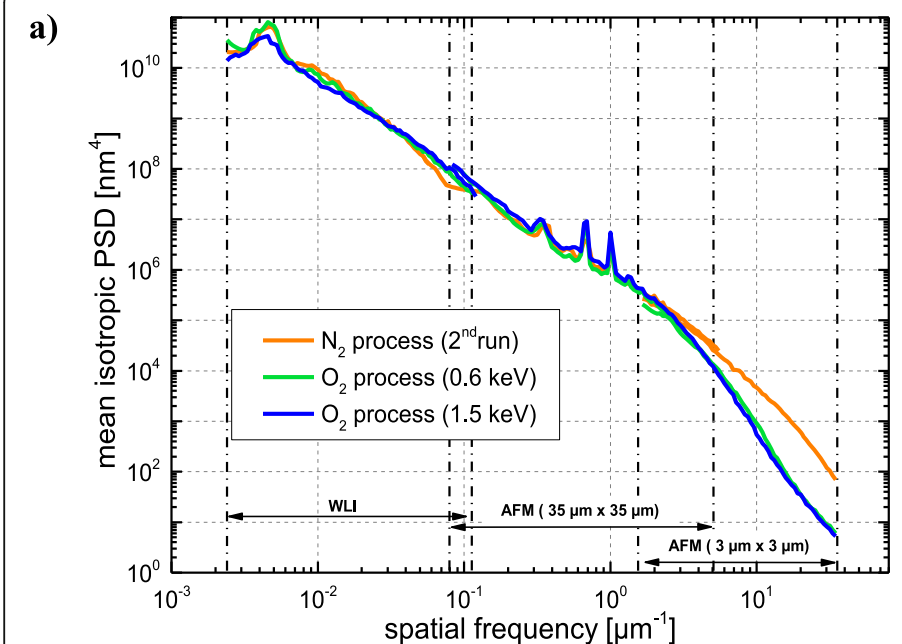

b)

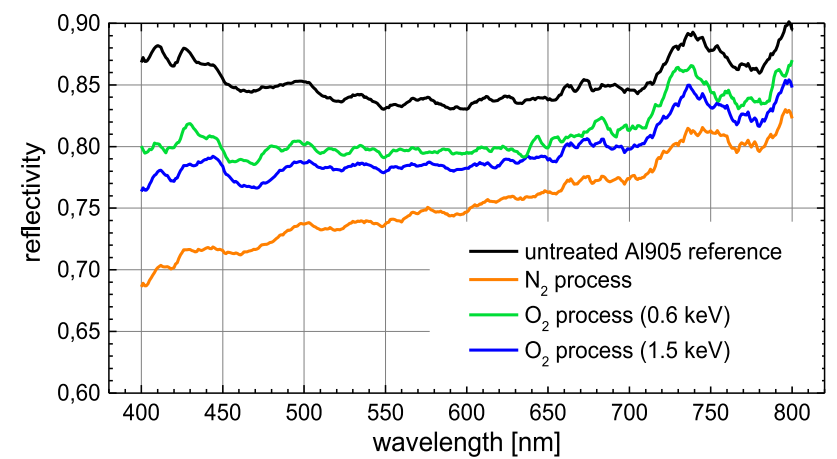

c)

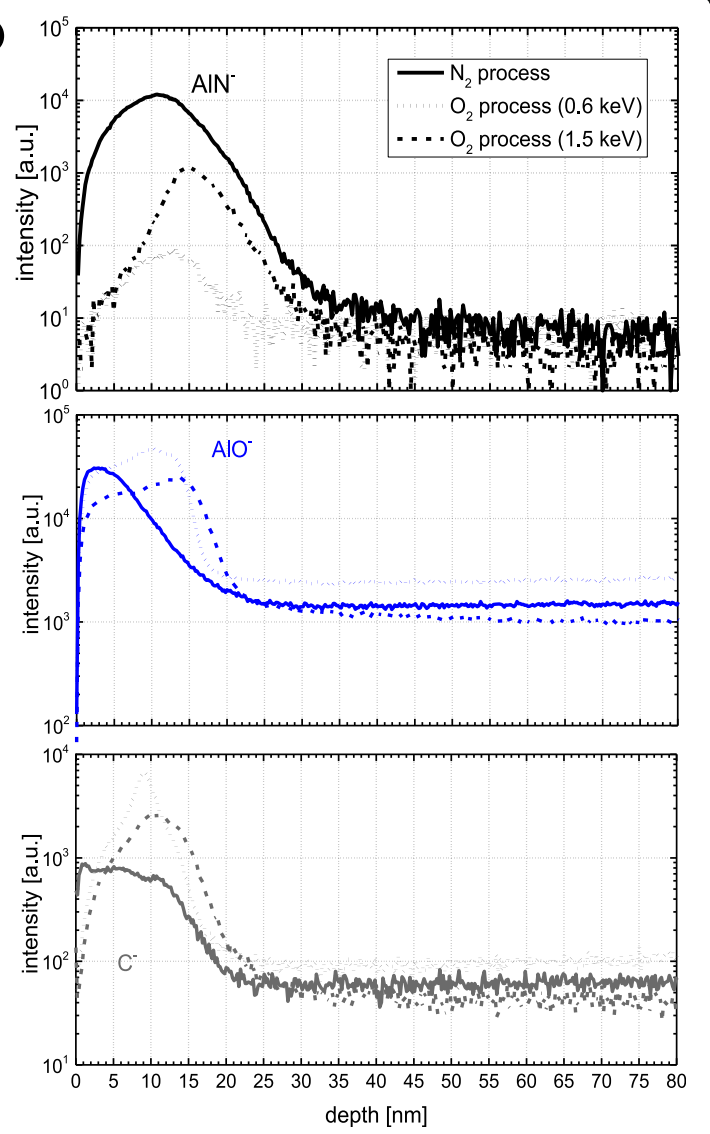

Fig. 10 Investigations on ion beam planarization and $\mathrm{O}_{2}$ finishing of Al905. The evolution of (a) PSD spectra, (b) reflectivity in the visible wavelength range and c) local chemical composition via ToF-SIMS of the initial surface, after two runs ion beam planarization with $\mathrm{N}_{2}$ and subsequent $\mathrm{O}_{2}$ finishing at beam voltages of $0.6 \mathrm{keV}$ and $1.5 \mathrm{keV}$, respectively, are shown

above $2 \mu \mathrm{m}^{-1}$ to maximum 1.5 orders of magnitude resulting in a reduction of the surface errors situated in the microroughness regime.

ToF-SIMS depth profiling further reveal similar nitride layer formation during RIBE planarization resulting in $15.3 \mathrm{~nm}$ thickness, as already observed during $\mathrm{N}_{2}$ RIBE machining discussed in section 3.1 (see Fig. 10c). During $\mathrm{O}_{2}$ finishing at $1.5 \mathrm{keV}$, the oxide layer is enlarged to $16.8 \mathrm{~nm}$ and an overall improvement of the reflectivity in the analyzed visible wavelength range is observed. Consequently, subsequently applied $\mathrm{O}_{2}$ finishing at 1.5 $\mathrm{keV}$ leads to comparable results as discussed in section 3.2. In contrast, reflectivity measurements shown in Fig. 10b indicate a slightly further enhanced improvement in the whole measured wavelength range, when $0.6 \mathrm{keV}$ are applied in comparison to the investigations at $1.5 \mathrm{keV}$. The observed reflectivity improvement might result from the proceeding reduction of the nitride fraction and the reduced carbon incorporation depth shown in Fig. 10c. A comparison of both beam energies reveal a reduced oxide layer formation of $14.4 \mathrm{~nm}$ during $\mathrm{O}_{2}$ RIBE machining with $0.6 \mathrm{keV}$ beam energy since the penetration depth of oxygen within the nitride layer formed during $\mathrm{N}_{2}$ RIBE is lower than with $1.5 \mathrm{keV}$ beam energy. Though, the reduction of the nitride layer formed during RIBE planarization is more effective when lower beam energy is applied during $\mathrm{O}_{2}$ finishing.

\section{Summary}

An extension of the RIBE-based model scheme for ion beam figuring of optical aluminium surfaces using nitrogen was examined. In comparison to RIBE-based figuring with oxygen, the surface topography is preserved up to $1 \mu \mathrm{m}$ material removal depth. Additionally, an improvement of the surface topography was found for the turning mark features, which are smoothed out to some extent during ion beam machining. Marginal surface degradation caused by the formation of etch pits in the spatial frequency range of $0.27 \mu \mathrm{m}^{-1}-2.5 \mu \mathrm{m}^{-1}$ was observed after $1 \mu \mathrm{m}$ material removal. The formation of a $(14.7 \pm 0.9) \mathrm{nm}$ thick aluminium nitride layer seems to act as a passivation layer. The surface nitride layer is eroded and simultaneously newly formed during machining. Irrespective of the material removal depth, the 
microroughness was increased in the spatial frequency range of $2.5 \mu \mathrm{m}^{-1}-34.7 \mu \mathrm{m}^{-1}$ caused by the formation of a granular structure. Investigations on $\mathrm{O}_{2}$ finishing were performed subsequently on the samples after direct $\mathrm{N}_{2}$ machining. The PSD function was decreased in the spatial frequency range of $2.5 \mu \mathrm{m}^{-1}-34.7 \mu \mathrm{m}^{-1}$ up to a machining depth of about $120 \mathrm{~nm}$ with $1.5 \mathrm{keV}$ beam energy, whereas no distinct surface degradation was observed. The oxide layer formed had a thickness of about $16 \mathrm{~nm}$ already after one repetition and was pretty constant with increasing material removal. Additionally, the reflectivity was significantly improved during subsequent oxygen finishing.

During ion beam planarization performed at $1.2 \mathrm{keV}$ with nitrogen, the turning mark structures were successfully reduced. However, the surface microroughness showed comparable degradation due to the formation of a granular structure. ToF-SIMS measurements further revealed similar nitride layer formation and a reduced reflectivity. During subsequently applied $\mathrm{O}_{2}$ finishing procedure at $1.5 \mathrm{keV}$, the PSD function is strongly decreased in the spatial frequency range above $2 \mu \mathrm{m}^{-1}$ and the reflectivity is significantly improved. However, investigations at $0.6 \mathrm{keV}$ revealed further improvement of the reflectivity, while the surface features in the microroughness regime are smoothed to a similar extent. Consequently, marginal material removal during ion beam irradiation at a low energy of $0.6 \mathrm{keV}$ was sufficient to almost recover the surface quality of an untreated optical aluminium surface again. The RIBE finishing technology can therefore be extended to include nitrogen process gas requiring two consecutive process steps. Furthermore, the subsequently applied $\mathrm{O}_{2}$ finishing procedure not only restores the reflective properties, but also increases the long-term stability. Distinct improvement of the reflectivity was observed on RSA Al905 surfaces irradiated with $\mathrm{N}_{2}$, when the sample was stored under lab conditions in air. The enrichment of the surfaces revealing significant oxidation during subsequently applied $\mathrm{O}_{2}$ finishing showed distinctly improved reflection properties that hardly change over time.

\section{Abbreviations \\ AFM: Atomic force microscopy; FWHM: Full width at half maximum; IR: Infrared; NiP: Nickel phosphorous; PSD: Power spectral density; RF: Radio frequency; RIBE: Reactive ion beam etching; RMS: Root mean square; RSA: Rapidly solidified aluminium; SPDT: Single-point diamond turning; ToF- SIMS: Time-of flight secondary ion mass spectrometry; UV: Ultraviolet; WLI: White light interferometry}

\section{Acknowledgements}

The authors are very grateful to Mr. T. Liebeskind for sample preparation. Gratefully acknowledged is the financial support by the German Federal Ministry of Education and Research (BMBF) within the framework of the
InnoProfile Transfer initiative [03IPT706X] 'Ultra-precision manufacturing using atomic particle beams'.

\section{Authors' contributions}

MU conducted the experiments on RIBE and engaged in writing, JB performed ToF-SIMS measurements, experiments on RIBE and provided expert advice, FF provided important information for interpretation and discussion of the results and expert advice, TA coordinated the work. The authors have read and approved the final manuscript.

\section{Funding}

Financial support by the German Federal Ministry of Education and Research (BMBF) within the framework of the InnoProfile Transfer initiative 03IPT706X

'Ultra-precision manufacturing using atomic particle beams' is gratefully acknowledged.

\section{Availability of data and materials}

All data generated or analysed during this study are included in this published article.

\section{Competing interests}

The authors declare that they have no competing interests.

\section{Author details}

${ }^{1}$ Leibniz Institute of Surface Engineering (IOM), Permoserstr. 15, 04318

Leipzig, Germany. ${ }^{2}$ Technische Universität Dresden, Institute of

Manufacturing Science and Engineering, 01069 Dresden, Germany.

Received: 27 January 2020 Accepted: 14 August 2020

Published online: 04 January 2021

\section{References}

1. Klocek, P. (ed.): Handbook of Infrared Optical Materials. CRC Press, New York (1991)

2. Yin, Z., Yi, Z.: Direct polishing of aluminium mirrors with higher quality and accuracy. Appl. Optics. 54, 7835-7841 (2015). https://doi.org/10.1364/AO.54. 007835

3. Delplancke, F., Nijenhuis, J., de Man, H., Andolfato, L., Treichel, R., Hopman, J., Derie, F.: Star separator system for the dual-field capability (PRIMA) of the VLTI. Proc. SPIE-Int. Soc. Opt. Eng. 5491, 1528-1535 (2004). https://doi.org/ $10.1117 / 12.551873$

4. ter Horst, R., Tromp, N., de Haan, M., Navarro, R., Venema, L., Pragt, J.: Directly polished lightweight aluminium mirror. Proc. SPIE-Int. Soc. Opt. Eng. 105660P, 10566 (2017). https://doi.org/10.1117/12.2308200

5. Kinast, J., Schlegel, R., Kleinbauer, K., Steinkopf, R., Follert, R., Dorn, R.J., Lizon, J.L., Hatzes, A., Tünnermann, A.: Manufacturing of aluminum mirrors for cryogenic applications. Proc. SPIE-Int. Soc. Opt. Eng. 10706, 107063G (2018). https://doi.org/10.1117/12.2313126

6. Supranowitz, C., Hall, C., Dumas, P., Hallock, B.: Improving surface figure and microroughness of IR materials and diamond turned surfaces with magnetorheological finishing (MRF). Proc. SPIE-Int. Soc. Opt. Eng. 6545, 65450S (2007). https://doi.org/10.1117/12.719792

7. Folkman, S.L.: Characterization of electroless nickel plating on aluminum mirrors. Proc. SPIE-Int Soc. Opt. Eng. 4771, 254-264 (2002). https://doi.org/ $10.1117 / 12.482167$

8. Bauer, J., Frost, F., Arnold, T.: Reactive ion beam figuring of optical aluminium surfaces. J. Phys. D Appl. Phys. 50(8), 85101 (2017). https://doi. org/10.1088/1361-6463/50/8/085101

9. Bauer, J., Frost, F., Lehmann, A., Ulitschka, M., Li, Y., Arnold, T.: Finishing of metal optics by ion beam technologies. Optim. Eng. 58(9), 092612 (2019). https://doi.org/10.1117/1.OE.58.9.092612

10. Bauer, J., Ulitschka, M., Pietag, F., Arnold, T.: Improved ion beam tools for ultraprecision figure correction of curved aluminum mirror surfaces. J. Astron. Telesc. Instrum. Syst. 4(4), 046003 (2018). https://doi.org/10.1117/1. JATIS.4.4.046003

11. Ulitschka, M., Bauer, J., Frost, F., Arnold, T.: Reactive ion beam etching-based planarization of optical aluminium surfaces. Proc. SPIE-Int. Soc. Opt. Eng. 11032, 110320D (2019). https://doi.org/10.1117/12.2513670

12. Bauer, J., Ulitschka, M., Frost, F., Arnold, T.: Figuring of optical aluminium devices by reactive ion beam etching. EPJ Web Conf. 215(6002), (2019). https://doi.org/10.1051/epjconf/201921506002 
13. Nobes, M.J., Colligon, J.S., Carter, G.: The equilibrium topography of sputtered amorphous solids. J. Mater. Sci. 4, 730-733 (1969). https://doi.org/ 10.1007/BF02403410

14. Carter, G., Colligon, J.S., Nobes, M.J.: The equilibrium topography of sputtered amorphous solids II. J. Mater. Sci. 6, 115-117 (1971). https://doi. org/10.1007/BF00550340

15. Carter, G., Nobes, M.J., Whitton, J.L.: The stability of equilibrium surface topography developed by sputtering. J. Mater. Sci. 13, 2725-2728 (1978) https://doi.org/10.1007/BF02402765

16. Carter, G.: The physics and applications of ion beam erosion. J. Phys. D Appl. Phys. 34, R1-R22 (2001). https://doi.org/10.1088/0022-3727/34/3/201

17. Carter, G., Nobes, M.J., Katardjiev, I.V.: Sputter polishing of surfaces. Phil. Mag. B 66, 419-425 (1992). https://doi.org/10.1080/13642819208207660

18. Ulitschka, M., Bauer, J., Frost, F., Arnold, T.: Local smoothing of optical aluminium surfaces by reactive ion beam etching. Optim. Eng. under review. 59(3), 035108 (2020). https://doi.org/10.1117/1.OE.59.3.035108

19. Johnson, L.F., Ingersoll, K.A., Kahng, D.: Planarization of patterned surfaces by ion beam erosion. Appl. Phys. Lett. 40, 636-638 (1982). https://doi.org/10. 1063/1.93172

20. Johnson, L.F., Ingersoll, K.A.: Ion polishing with the aid of a planarizing film. Appl. Optics. 22, 1165-1167 (1983). https://doi.org/10.1364/AO.22.001165

21. Ulitschka, M., Bauer, J., Frost, F., Arnold, T.: Ion beam planarization of optical aluminium surfaces. J. Astron. Telesc. Instrum. Syst. 6(1), 014001 (2020). https://doi.org/10.1117/1.JATIS.6.1.014001

22. Gubbels, G., Tegelaers, L., Senden, R.: Melt spun aluminium alloys for moulding optics. Proc. SPIE-Int Soc. Opt. Eng. 8884, 88841W (2013). https:// doi.org/10.1117/12.2030181

23. The Scanning Probe Image Processor SPIP ${ }^{\text {TM }}$, Image metrology, Denmark, https://www.imagemet.com/products/spip/. Accessed 11 Dec 2019

24. Thedsakhulwong, A., Locharoenrat, K., Thowladda, W.: Nitrogen concentrations on structural and optical properties of aluminum nitride films deposited by reactive RF-magnetron sputtering. Adv. Mat. Res. 631632, 186-191 (2013). https://doi.org/10.4028/www.scientific.net/AMR.631632.186

25. Bennett, H.E., Porteus, J.O.: Relation between surface roughness and specular reflectance at normal incidence. J. Opt. Soc. Am. 51, 123-129 (1961). https://doi.org/10.1364/JOSA.51.000123

26. Harvey, J.E., Thompson, A.K.: Scattering effects from residual optical fabrication errors. Proc. SPIE-Int. Soc. Opt. Eng. 2576, International Conference on Optical Fabrication and Testing, 155-174 (1995). https://doi. org/10.1117/12.215588

27. McCune, R.C., Donlon, W.T., Plummer Jr., H.K., Toth, L., Kunz, F.W.: Characterization of surface layers produced by ion implantation of nitrogen in bulk aluminium. Thin Solid Films. 168, 263and references therein (1989). https://doi.org/10.1016/0040-6090(89)90012-6

28. Sanghera, H.K., Sullivan, J.L., Saied, S.O.: A study of nitrogen implantation in aluminium-a comparison of experimental results and computer simulation. Appl. Surf. Sci. 141(1-2), 57-76 (1999). https://doi.org/10.1016/S01694332(98)00618-7

29. Möller, W., Parascandola, S., Telbizova, T., Günzel, R., Richter, E.: Surface processes and diffusion mechanisms of ion nitriding of stainless steel and aluminium. Surf. Coat. Technol. 136, 73-79 (2001). https://doi.org/10.1016/ S0257-8972(00)01015-X

30. Netterfield, R.P., Müller, K.-H., McKenzie, D.R., Goonan, M.J., Martin, P.J.: Growth dynamics of aluminum nitride and aluminum oxide thin films synthesized by ion-assisted deposition. Appl. Phys. 63(3), 760-769 (1988). https://doi.org/10.1063/1.340068

31. Taylor, J.A., Rabalais, J.W.: Reaction of $\mathrm{N}_{2}^{+}$beams with aluminum surfaces. J. Chem. Phys. 75, 1735 (1981). https://doi.org/10.1063/1.442251

32. Espinós, J.P., González-Elipe, A.R., Mohai, M., Bertóti, I.: Surface chemical effects of low-energy $\mathrm{N}_{2}^{+}$ion bombardment on single crystalline $\mathrm{a}-\mathrm{Al}_{2} \mathrm{O}_{3}$. Surf. Interface Anal. 30, 90-94 (2000). https://doi.org/10.1002/10969918(200008)30:1<90::AID-SIA796>3.0.CO;2-Q

33. Yeh, C.-T., Tuan, W.-H.: Oxidation mechanism of aluminium nitride revisited. J. Adv. Ceram. 6(1), 27-32 (2017). https://doi.org/10.1007/s40145-016-0213-1

34. Dutta, I., Mitra, S.: Oxidation of sintered aluminium nitride at near-ambient temperatures. J. Am. Ceram. Soc. 75(11), 3149-3153 (1992). https://doi.org/ 10.1111/j.1151-2916.1992.tb04403.x

35. Yue, R., Wang, Y., Wang, Y., Chen, C.: SIMS study on the initial oxidation process of AlN ceramic substrate in the air. Appl. Surf. Sci. 148(1-2), 73-78 (1999). https://doi.org/10.1016/S0169-4332(99)00128-2
36. Korbutowicz, R., Zakrzewski, A., Rac-Rumijowska, O., Stafiniak, A., Vincze, A.: Oxidation rates of aluminium nitride thin films: effect of composition of the atmosphere. J. Mater. Sci. Mater. Electron. 28, 13937-13949 (2017). https:// doi.org/10.1007/s10854-017-7243-5

37. Yamamura, Y., Tawara, H.: Energy dependence of ion-induced sputtering yields from monoatomic solids at normal incidence. At. Data Nucl. Data Tables. 62(2), 149-253 (1996). https://doi.org/10.1006/adnd.1996.0005

\section{Publisher's Note}

Springer Nature remains neutral with regard to jurisdictional claims in published maps and institutional affiliations.

\section{Submit your manuscript to a SpringerOpen ${ }^{\circ}$ journal and benefit from:}

- Convenient online submission

- Rigorous peer review

- Open access: articles freely available online

High visibility within the field

- Retaining the copyright to your article

Submit your next manuscript at $\boldsymbol{\nabla}$ springeropen.com 